\title{
Toward Modernization and Internationalization (M\&I) of Higher Education Institution
}

\author{
Gembong Baskoro ${ }^{1}$
}

\begin{abstract}
Knowledege based economy will be a matter of time for Indonesia's future competitiveness. Therefore, to get there, several basic requirements have to be early prepared. Among others, human capital is perhaps the most important requirement for a country to be able to develop an economic condition based on the capability and capacity of knowledge. Human capital is not just Indonesia concern, it is the concern of all countries. In fact, only some countries can create a condition for human capital to grow effectively and efficiently. Mostly, Higher Education Institution (HEI) or university is the main organization that has objective to develop human capital. The pupose of HEI is to develop academic and non-academic capability for student by mean of educating them with a structured curriculla. However, in today's environmental condition even with similar curriculla, any HEI may ends up with different quality. From this point of view, this paper will discuss and elaborate further on a policy and strategy that enable a HEI can create a competitive education environment for student to grow up to their best competitive conditions.
\end{abstract}

Keywords: Modernization, internationalization, higher education institution.

\section{Introduction}

The ultimate objective of the Republic of Indonesia is to pursue four main goals i.e. (1) protection to national interests, (2) prosperity, (3) education for all, and (4) security (Preambule of Indonesia Constitution 1945). To pursue the objectives, all resources, including but not limited to, its people (considered as subject and object) must be utilized effectively and efficiently. In order to be prosper, it is necessary that Indonesia must be competitive in all aspects. Among other aspects, economy is a main concern for recently and the coming years. Indonesia's economy policy and strategy are influenced by environmental conditions i.e. global, regional, and national. In the past, due to the advantage of low wages worker condition (including knowledge worker), as comparative advantages, Indonesia's economy has grown rapidly especially in industrial and production sectors. However, because of regional development nowaday, this situation is different. Regional countries are nowaday having competitive workers as well. As a consequence, some companies have shifted their production facilities to these countries. This situation in the future may impact to economic conditions if Indonesia human capacity stands still. ${ }^{1}$ Widya Kartika University. Л.. Sutorejo Prima Utara II-1.
Surabaya 60113. Email: gembong_baskoro@yahoo.com,

Received 30th September 2011; revised1 7th November 2011, revised2 22th August 2011; accepted for publication 30th November 2011.
In contrast, the leading countries have enjoyed prosperity for long time because of high capacity of their human capital. They have already shifted the economy strategy from production based into knowledge based economy with high wages of their knowledge workers. They have also relocated the production facilities mostly to low wages countries around the world. Looking at this global situation, therefore, it is necessary for Indonesia to prepare for shifting its economy strategy towards knowledge based economy in the near future. For this strategy to succeed requires strong Higher Education Institutions (HEI) or Universities as breeding facilities for high qualified human capital. Among other concepts that enable a university can breed high quality alumni, this paper stressess on Modernization and Internationalization (M\&I) of higher education institution as a policy or strategy.

\section{Methods}

\section{Reasoning}

This paper is aimed to conceptualize the need of M\&I for HEI. The reasoning is based on the fact that HEI is a main factor for a country to not only nurture and or educate future leaders but also to develop human civilization. HEI plays also a very important role in order to ensure a nation can realize the prosperity of its people as well as improving quality of life. The success of this role is indicated by, for example, Human Development Index (HDI). However, it is important to note that HEI is not the 
only factor contributing to the HDI index. Nowaday, Indonesia reportedly has suffered decreasing HDI index, released by United Nation Development Programme (UNDP), from 108 in 2010 to become 124 in 2011. Regardless questions and arguments concerning the decreasing of the index, in fact HEI still become an important indicator to measure country achievement in improving human capital. That is why this paper indicated the importance of HEI, as well as other indicator, as a measure of country competitiveness. For this reason, this paper proposing policy, concept, and strategy based on theories, real facts, case studies, and expert opinions to improve competitiveness by improving human capital through M\&I of HEI.

\section{Theory of Modernization}

"Modern" is a familiar term for everybody and it seemingly has many definitions attach to it. For example, the definition of "modern" may be described as a highly innovated thing. Other may describe modern as a "high-end" technological development of a thing. Modernization, by definition, is a process or action to make modern in any aspects e.g. technology, style, use, design, method, culture, mindset, etc. However, in this paper, modernization will be defined as a process of (individual) change into a set of condition that will impact to the transformation of quality of thinking and life. The process of (individual) change will be properly managed and driven by education. There are several theories related to modernization that can be referred to, such as:

\section{Classical Modernization Theory}

The classical modernization theory was discussed intensely in the year of $60 \mathrm{~s}$. This theory elaborates on the process of change in all human aspects, especially due to the impact of industrial revolution. In the classical modernization theory, the focal points are about transition from traditional (agriculture) civilization e.g. economy, society, politics, or culture into industrial (economy) civilization. However, as the progress of innovation in many aspects of life is moving forward, the industrial civilization is not the end point of human civilization. The human civilization is always progressing, therefore the classical theory of modernization is chalanged, may be replaced, with post modernization theory. The characteristic of the classical modernization can be seen in Table 1.

\section{Post Modernization Theory}

The post modernization theory further looking at the modernization after the industrial civilization.
Table 1. Characteristic of the classical modernization (He Chuanqi [7])

\begin{tabular}{l} 
Elements \\
\hline Definition $\begin{array}{l}\text { Classical modernization is the histocial process } \\
\text { of the great changes of the transformation from } \\
\text { traditional agricultural to the modern industrial } \\
\text { society since the industrial revolution in } 18^{\text {th }} \\
\text { century }\end{array}$
\end{tabular}

Process The process is revolutionalry, complex, systematic, global, long-term and progressive (Huntington [10])

Results The crystallization and diffusion of the classical modernity. The classical modernity is the collection of the characteristics of the nations who have finished the classical modernization.

Dynamics There are three schools: economy-decision, culture-decision and the cooperative decision of the economy, politics and culture (Inglehart [11])

Pattern There ar more than seven patterns, and were path dependable (Black [1])

Resource: Group of China Modernization Study [6], China

Therefore, post modernization indicates an advanced industrial civilization. There are no clear cut boundary between the stages of industrial with advanced industrial. Indication of an advanced industrial is about the transformation into a process that are more effective and efficient, more automatic, less human involved, more flexibility, as well as more troughput. In term of mindset and culture, advanced industrial can be regarded as highly technological involvement, less direct interaction, environment friendly, globalized process and sources, as well as more caring to human by means of social responsibility. The post modernization theory, therefore, can be regarded as an advanced civilization that enable faster economic, cultural, and political change in a society. Perhaps, this is the driver of globalization that opens a new boundary of human interaction and civilization in a broader sense (Dirlik, [4]). Inglehart, [11] indicated that moderni-zation is not linear. Inglehart, [11] also described the changes in advanced industrial society since 1970 as the Postmodernization.

\section{Second Modernization Theory}

The second modernization theory suggested in 1998 by China scientist, He Chuanqi [8]. He divided the human development process into: Tool Age, Agriculture Age, Industrial Age and Knowledge Age. He also correlated every Ages into a life cycle curve and composed by four phases: start phase, development phase, mature phase and transition phase. He then divided, the human development process into two stages: first modernization, and second modernization. The first modernization is the transformation from agriculture phase into industrial phase. Second modernization is the transforma- 
tion from industrial phase into knowledge phase. He Chuanqi [8] considered four elements in every transformation e.g. society, economy, civilization, and then Age. He Chuanqi [9] described the characteristic of the second modernization as in Table 2.

\section{Internationalization and Globalization Theory}

Internationalization can be interpreted in many different ways. The interpretation of internationalization vary depends on many factors including, but not limited to, ideology, political, economy, social and culture, or even defence and security. For Indonesia, internationalization in HEI has been known since the age of colonialism long time before the independence. At that time, internationalization in HEI was defined as a very limited opportunity for Indonesian to study abroad especially to Dutch universities. It was an academic mobility concept. However, nowaday, internationalization is a term that is used alongside with globalization (Dirlik [4]). Therefore, in order to understand internationalization it requires comprehensive understanding of globalization itself. It is not necessarry to make clear distinction between internationalization and globalization because they can be overlapped each other. Intuitively, the meaning of internationalization nowaday has been shifted because of major global economic trends and influence of commercialization. There are two different perspectives to understand the meaning of internationalization and globalization i.e. the positive or negative perspective. Internationalization for HEI is a situation that enable a HEI accept foreign students, deliver the course in English, compatibility of curriculum with international standard, International academic and research exchange, International reputation, etc. While globalization, involves international production, market, investment, trade, etc. across border either done by transnational companies or any other organizations. Therefore, one indicator of globalization is the internationalization itself.

There are many arguments either advantage and or disadvantage of involving globalization and internationalization of HEI. This paper considers on the differrent view, this paper indicates that both globalization and internationalization is unavoidable to any country, it just a matter of time for a country to adjust and adapt to the changing world. Therefore, HEI also requires adaptation to this situation and stresses on the advantage factors and reduce the disadvantages. The advantages of international and globalization are that students, lecturers, and universities will be counted as an active partner in global education community. The chalange in internationalization, not disadvantages, is about preserving local/national culture.
Table 2. Second modernization (He, Chuanqi [7])

\begin{tabular}{l} 
Elements \\
\hline Definition General modernization is both the process of the \\
great changes of the human civilization since the \\
industrial revolusion in $18^{\text {th }}$ century, which \\
includes the transformations from traditional to \\
modern society, economy, politics and civiliza- \\
tion, and the process of the reaching, keeping \\
and catching-up with the frontier level of the \\
global civilization at national and regional level. \\
There are two phases of the general moderni- \\
zations from $18^{\text {th }}$ century to the end of $21^{\text {st }}$ \\
century, and the first modernization was the \\
process of the great transformation from \\
agriculture to industrial civilization, the second \\
modernization was the process of the great \\
transformation from industrial to Knowledge \\
civilization. The economic growth is the top \\
issue, the quality of material life will converge, \\
the styles of the spiritual and cultural life will \\
be highly diversified in the second moderni- \\
zation.
\end{tabular}

Results The crystallization and diffusion of the first modernity is one kind of the results of the first modernization. The crystallization and diffusion of the second modernity is one kind of the results of the second modernization, the characteristics of the second modernity are coming into view.

Dynamics The dynamics of the first modernization is the capital, technology and democracy, etc. The dynamics of the second modernization is the knowledge and institutional innovation and human capital, etc.

Pattern There are many pattern both in the two phases of the modernization, they are the path dependence, and the comprehensive modernization will be the strategic choice for the developing countries.

Resource: Group of China Modernization Study [6], China

\section{Result and Discussion}

Modernization and Internationalization (M\&I) can be considered as a possible strategy especially for Higher Education Institution (HEI) to ensure that future development of HEI aligns with global environmental changing. One of the reason is that it is predicted that in order to be competitive in the global environmental changing requires highly competitive human capital. However, globalization can bring negative impacts related to value preservation. Therefore, M\&I must align with local/national culture and values especially to sociocultural values.

\section{Why do Modernization and Intenationaliza- tion?}

This is a critical question regarding the urgency to reform HEI by means of M\&I and why this is considered important?. The urgency to reform HEI 
Table 3. Indexes of Indonesia Development Indicator [3,12,15,16]

\begin{tabular}{|c|c|c|c|c|c|c|c|}
\hline \multirow[b]{3}{*}{ Country } & \multicolumn{7}{|c|}{ RANK on year 2010 from 139 countries (unless indicated differently) } \\
\hline & \multirow{2}{*}{$\begin{array}{c}\text { Population }{ }^{1} \\
\text { (2009) }\end{array}$} & \multirow{2}{*}{$\begin{array}{c}\text { GDP }^{2} \\
\text { Per Kapita }\end{array}$} & $\mathrm{GCl}^{3}$ & \multirow{2}{*}{$\begin{array}{c}\mathrm{HDI}^{4} \\
\text { (169 Cty.) }\end{array}$} & \multirow{2}{*}{$\begin{array}{l}\mathrm{GI}^{5} \text { (2011) } \\
\text { (125 Cty.) }\end{array}$} & \multirow{2}{*}{$\begin{array}{l}\mathrm{EDI}^{6}(2008) \\
\text { (127 Cty.) }\end{array}$} & \multirow{2}{*}{$\begin{array}{c}\mathrm{CPI}^{7} \\
\text { (178 Cty.) }\end{array}$} \\
\hline & & & Total & & & & \\
\hline China & $\sqrt{2}$ & Y 87 & $\Rightarrow 27$ & Y 89 & 29 & $\nabla 66$ & \& 3,5 \\
\hline India & צ & \& 112 & 凡 51 & \& 119 & 62 & \& 107 & \& 3,3 \\
\hline USA & $\Rightarrow$ & 仓 9 & 仓 4 & ن 9 & 仓 & 13 33 & 7,1 \\
\hline Indonesia & 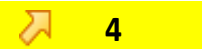 & 100 & Y44 & 108 & 99 & $\Rightarrow 69$ & 2,8 \\
\hline Brazil & 它 & $\Rightarrow 57$ & $\sqrt{58}$ & У 73 & \ 47 & \88 & $\ 3,7$ \\
\hline \multicolumn{8}{|c|}{ Note: } \\
\hline \multicolumn{8}{|c|}{ 1: Global Competitiveness Index (GCI); Klaus Schwab, The Global Competitiveness Report 2010-2011, WEF } \\
\hline \multicolumn{8}{|c|}{ 2: Ibid 1} \\
\hline \multicolumn{8}{|c|}{ 3: Ibid 1} \\
\hline \multicolumn{8}{|c|}{ 4: UNDP Releases 2010 Human Development Index (HDI) } \\
\hline \multicolumn{8}{|c|}{ 5: Global Innovation Index (GII), INSEAD } \\
\hline \multicolumn{8}{|c|}{ 6: Education For All Development Index (EDI), EFA Monitoring report 2011, UNESCO } \\
\hline \multicolumn{8}{|c|}{ 7: Corruption Perception Index (CPI), Transparency International } \\
\hline
\end{tabular}

based on the fact that the indexes to measure Indonesia's development (Tabel 3) in term of i.e. Human Development Index (HDI), Education Development Index (EDI), Global Innovation Index (GII), Global Competitiveness Index (GCI), and Corruption Perception Index (CPI) are considered low, therefore they need an improvement effort. These indexes can be used to indicate the situation of today competitiveness, on the basis of the rate of change of the population, and also can be used to make prediction for future situation. Although no exact figure regarding the changing of future environmental conditions especially on economy, still it can be predicted that in the future the (economy) competition will be more thougher especially related to the knowledge based economy. Therefore, there is no better choices than to prepare the future human capital by improving the capability and capacaty through the concept of M\&I in HEI.

\section{How to Align Modernization and Internationa- lization with Cultural Values?}

This question related to the negative impact of M\&I that possibly misinterpreted as "Westernization" including either "Americanization" or "Europeanization". If this is the case then the point of misinterpretation regarding "westernization" will be on the culture and values. M\&I, in this paper, must be seen as strategy to ensure effectiveness and efficiency of HEI to nurture high qualified of human capital regardless the impact of other factors. If, of course, there is impact on the cultural values as a result of $M \& I$ then the impact must be handled separately. It is not unsual that any effort to make a change in organization free from impact or influences. It is common that the impact of any effort (policy, strategy, or action) should be included in the consideration of a policy/strategy or concept development. What is important to be considered is that the benefit of this policy or strategy for longer period and its influence to community is better than making no change to the present situation of HEI.

\section{What It is Expected to Looks Like?}

The modernization and transformation of HEI to become internationally recognized can be seen from two points of view i.e. (1) on the soft aspects and (2) on the hard aspects. On the soft aspects, M\&I is expected to influence on the individual thinking that is strenghtening the value of pluralism, understanding of other, working in international environment, cross culture understanding, etc. While on the hard aspects, M\&I is expected to improve the quality of technology of education into a standard and modern technology. The expectation is that M\&I can influence along the process of the HEI system that includes Input, Process, Output, Outcome, and Impact. However, one should remember that the ultimate goal of HEI is to educate young people in any field so that they can transform themselves into a certain level of academic competences, according to design curriculla, as well as to enable them to grow to non-academic competences such as any soft skills. Therefore, to enable that, the circumtances during the educational process must be managed to an optimal condition. 


\section{Conclusion}

The important consideration related to the M\&I policy or strategy is that to enable effectiveness of educational process requires well management of the following factors: people, environment, system, and supports. Well management of these factors can create a culture of quality (Campell and Rozsnyani [2]). This is expected to happen in any education including but not limited to HEI. Furthermore, influence of external factor e.g. government policy is also considered important to the effectiveness of the educational process. However, the M\&I policy has some drawbacks. For example, it requires financial capability especially related to modernization of technology used for education. Therefore, it is important to have reasonable financial backup whether from govern-ment or private sources in order to implement the M\&I policy.

Furthermore the concept of M\&I may be correlated to HEI management standard in Western Countries. However, in the context of M\&I, nowaday China is also moving to the same direction as of Western. In comparison to Western and China HEI, it is observed subjectively that eventhough Indonesia's HEI already modernized and internationalized, there is still a gap compared to both of them.

Therefore, this paper tries to conclude that M\&I is a policy or a strategy for HEI to be competitive nowaday and the coming years. Therefore, HEIs should not wait any longer to modernize and internationalize themselves. Otherwise, the gap between Indonesia's HEI with Western and/or China HEI is getting more difficult to follow. If HEIs fail to modernize themselves, they face the possibility to get trap into dependency of the modernization age by others sources in order for them to cope with the changing of society and other environmental factors. This situation has been further discussed by Frank [4] on the theory of dependency as a contradiction or negation of the modernization theory.

Modernization is actually the development of civilization that stresses from the transition to a knowledge based society (Nils, [13]; Huntington, [10]). While Internationalization is actually the foundation to live in a small village of globalization (Huntington, [10]).

\section{References}

1. Black, C. E., The Dynamics of Modernization. New York, New York: Harper and Row Publishers, 1966

2. Campell and Rozsnyani, Quality Assurance and the Development of Course Programs. Papers on Higher Education, Unesco-CEPES, Bucharest, 2002.

3. Corruption Perception Index 2011, Transparency International, www.transparency.org

4. Dirlik, A., Modernity: From Modernization to Globalization, SID (Society for International Development), 2002.

5. Frank A. G., Crisis in the Third World. New York. Holmes and Meier, 1967.

6. Group of China Modernization Study, China Modernization Report 2004, Beijing: Peking University Press, 2004.

7. He, Chuanqi., The Civilization and Modernization, 36th World Congress of International Institute of Sociolog, China Modernization Report 2004, Beijing, 2004.

8. He, Chuanqi, Knowledge Economy and China's Modernization. Guangming Daily, 1998, pp.04-17.

9. He, Chuanqi, Second Modernization: Inspiration from Human Civilization Process. Beijing: High Education Press, 1999.

10. Huntington, S. P., Modernization Development and Politics, from Modernization to Globalization. eds. T. Roberts and A. Hite, Blackwell Publishing, London, 1971.

11. Inglehart R., Modernization and Postmodernization: Cultural, Economic, and Political Change in 43 Societies. Princeton University Press, 1997.

12. Klaus, The Global Competitiveness Report 20102011. (C) 2010 World Economic Forum, 2010.

13. Nils G., Mandarins of the Future: Modernization Theory in Cold War America. The Johns Hopkins University Press, Baltimore, USA, 2003.

14. Wallerstein, I., The Modern World System I: Capitalist Agriculture and the Origins of the European World-Economy in the Sixteenth Century. New York: Academic Press, 1974.

15. Wallerstein, I., Global Innovation Index 2009-10. INSEAD, 2009.

16. Wallerstein, I., EFA Monitoring Report 2011. UNESCO, 2011. 